\title{
Persistence early and late in extinction as a function of number of continuous reinforcements preceding partial reinforcement training*
}

\author{
KENNETH L. TRAUPMANN $\dagger$ \\ Department of Psychiary. Vew York Liniversity . Vedical Center \\ 550 First Avenue. Jew York. Tew York 10016 \\ ABRAM AMSEL \\ Liniversity of Texas, Austin. Texas 78712
}

and

PAUL T. P. WONG

Trent Liniversitw. Peterborough. Ontario. Canada

\begin{abstract}
In two experiments rats were given straight-alley training in the following sequence: continuous reward (CR), partial reward (PR). extinction (EXT). Independent groups differed only in the amount of CR training. In both experiments. early-EXT performance was directly related to amount of CR training and late-EXT performance was inversely related to amount of $C R$ training. These data were related to a possible specific $s_{F}$ intensity hypothesis, an extension of frustration theory.
\end{abstract}

Sutherland and MacKintosh (1971, p. 385) have presented several findings that they claim are contrary to a frustration theory interpretation of the partial reinforcement extinction effect. Among these is that, given the experimental paradigm in which continuous reward (CR), partial reward (PR). and extinction (EXT) are presented in sequence, resistance to extinction is inversely related to the amount of CR training that precedes PR. Since this important finding has apparently been reported only twice and in rather different contexts (Hothersall, 1966; Sutherland. MacKintosh, \& Wolfe, 1965), ${ }^{1}$ it was felt that further investigation was in order. Accordingly, two experiments were conducted in which number of $C R$ trials was varied in the first phase. followed by a constant number of PR trials and extinction.

\section{EXPERIMENT I}

Method

\section{Subjects}

The Si were 20 male albino rats. approsimately 90 days old. obtained from Holtzman Varms. Madison. Wisconsin. They were caged individually and had water arailable at all times.

\section{Apparatus}

The apparatus was a 6-ft 3 -in. black alles. 3 in. wide and 4 in. high. covered with clear Plexiglas. Separating the runway from a $3 \times 6$ in. gray startbox was a clear Plexiglas door. A black retrace door was situated 18 in. from the goal end of the runway. and a

*This research was supported by Grant GB-14990X from the National Science l oundation.

$\div$ Requests for reprints should be addressed to A. Amsel. Department of Psychology. Lniversity of Tevas. Austin. Teval 78712.
Li-shaped metal foodcup was positioned $1 \frac{1 / 2}{2}$ in. from the floor on the end wall.

A start measure reflected the photocell time from opening the start door to the interruption of a photobeam located 12 in. into the alles. Two remaining timers were activated by photocells situated $4 \mathrm{ft}$ and $6 \mathrm{ft}$ from the startbox door. providing run and goal measures.

\section{Procedure}

For 20 days prior to the experiment, Ss were adjusted to a 12-g daily deprivation diet of Wayne lab chow. During this period they were occasionally removed from their home cages and gentled.

Runway training was given at four trials a day, eithet for 16 CR trials followed by 32 PR trials (Group 16-32) or for 64 CR trials followed by $32 \mathrm{PR}$ trials (Group 64-32). CR training for Group 64-32 started before CR training for Group 16-32 so that PR training and $\mathrm{EXT}$ were given at the same time for both groups.

The Si were run in squads of five. providing an intertrial inter al of approximately 5 min. During PR training. rewarded $(R)$ and nonrewarded $(N)$ trials were randomly scheduled. with the restriction that two $R$ and two $N$ trials were given each day and, over the entire training, RR. RN. NR. and NN transitions were equated. On $\mathrm{N}$ trials. Ss were retained in the goalbox for $30 \mathrm{sec}$

Extinction was conducted at four trials a day for 40 trials or until $S$ took longer than $60 \mathrm{sec}$ to traverse any segment on two consecutive trials. If $\mathrm{S}$ reached this criterion. it was eliminated from the experiment and scores of 60 sec were given for each segment on all remaining trials.

\section{Results and Discussion}

Analyses of variance were conducted on reciprocals of the time scores. Since the data from all three measures were highly similar. we present data on!y from the first segment (start).

The top panel of Fig. 1 shows the reciprocal start times for terminal acquisition (TA) and EYT in blocks 


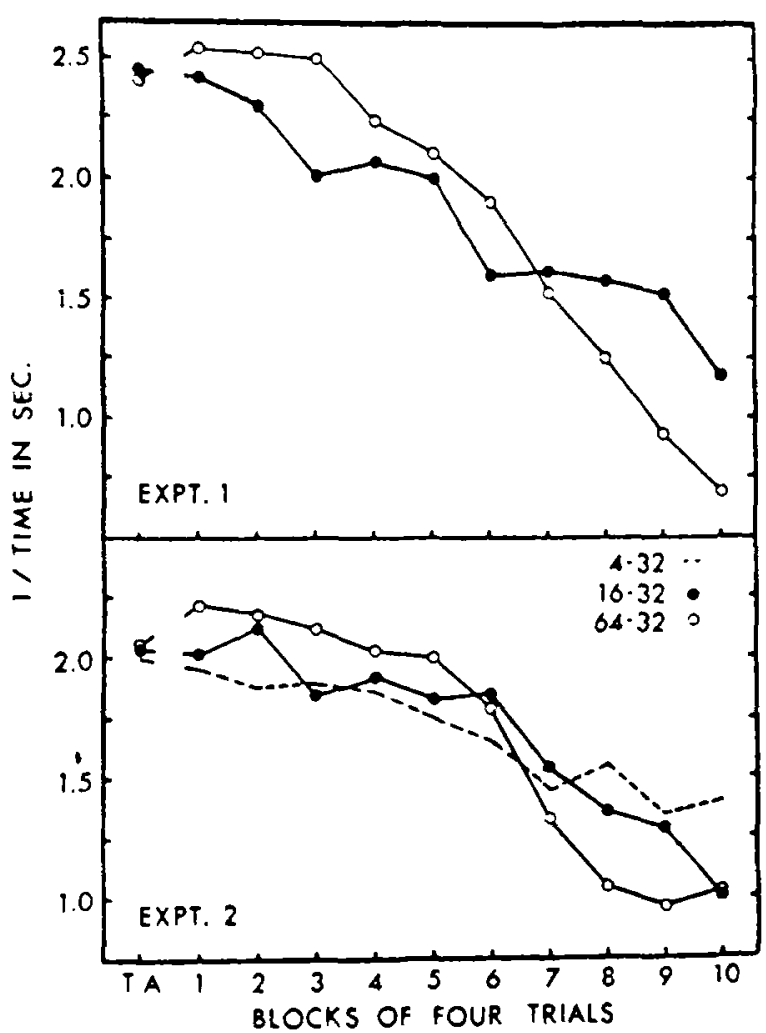

Fig. 1. Reciprocal start times in blocks of four trials for terminal acquisition $(T A)$ and extinction.

of four trials. These data seem clear in two respects. First. there was no reliable difference between Groups 16.32 and 64.32 at terminal acquisition. Second, and more surprising. while Group 64-32 ran faster than Group 16.32 in early EXT. the reverse is true in late EXT. This is reflected in a significant Groups by Days interaction $[F(9.702)=7.29 . p<.01]$. Simple-effects tests confirmed that the between-groups differences in extinition were reliable in one direction over Days 1.4 $\{F(1.702)=4.03, p<.05\}$ and in another direction over Days $7.10[F(1.702)=6.41 . p<.01]$.

The late-EXT superiority of Group 16.32 is consistent with the findings of both Sutherland et al (1965) and Hothersall (1966): however. the early-EXT superiority of Group 64-32 is clearly not in line with the Sutherland et al findings. Hothersall did not present EXT response rates. so that comparisons of early-EXT responding cannot be made between our experiment and his.

According to frustration theory (e.g., Amsel, 1967). increased resistance to extinction following PR training depends on the counterconditioning of approach to s.. . The theory also holds that the intensity of primary $\left(R_{\mathbf{l}}\right)$ and. therefore. conditioned $\left(\mathrm{r}_{\mathrm{H}}\right)$ frustration elicited during PR training depends upon the number of preceding $C R$ trials and the magnitude of reward on those trials. Given the CR-PR-EXT paradigm, it follows that $R_{A \text { pproach }}$ will be counterconditioned to stronger intensities of $S F$ following long-CR training than following short-CR training. Sutherland and MacKintosh
(1971) agree that frustration theory implies a direct relationship between resistance to extinction and intensity of $s_{1}$ : $t 0$ which $R_{\text {Approach }}$ is counterconditioned. This argues for a direct relationship between level of persistence and number of CR training trials. Their own earlier investigation, using the CR-PR-EXT paradigm. failed to confirm this prediction for the case of $100 \mathrm{CR}$ followed by $60 \mathrm{PR}$ trials vs 60 PR trials alone.

However, another possibility exists that does account for our findings in (admittedly ad hoc) frustration theoretic terms. This is the idea that $R_{A p p r o a c h}$ is counterconditioned to specific $\mathrm{s}_{\mathrm{F}}$ intensities during $\mathrm{PR}$ training (see Amsel. 1967: Traupmann. Wong. \& Amsel. 1971 ) and that persistence is determined at any phase of extinction by the similarity of the specific intensity of $s_{I}$ present to the intensity of $s_{F}$ to which $R_{A \text { pproach }}$ was counterconditioned during $P R$ training. According to such an analysis. $\mathbf{R}_{\mathrm{A} \text { pproach }}$ should have been counterconditioned to levels of $\mathrm{s}_{\mathrm{F}}$ in the moderate range for Group 16-32. since $16 \mathrm{CR}$ trials might be expected to produce mild $R_{F}$ on earlier nonsewarded trials in $P R$ training and 32 PR trials would serve to condition $r_{l}-s_{\mid}$ intensity to some moderate level (on a dimension of weak-moderate-strong intensity). For Group 64-32. on the other hand, the $64 \mathrm{CR}$ trials should provide for a relatively intense $\mathrm{R}_{\mathrm{I}}$ and the $32 \mathrm{PR}$ trials should serve to counteriondition a greater $\mathrm{s}_{\mathrm{F}}$ : intensity. In extinction. $\mathrm{s}_{\mathrm{F}}$. is assumed to be relatively intense at the outset but weaker in the later stages. It follows from a specific $s_{\text {l }}$ intensity hypothesis that Group 64-32 should show relatively greater persistence during early extinction and relatively less persistence in later extinction than Group 16-32.

\section{EXPERIMENT II}

In Experiment 11 we attempted to replicate the findings of Experiment $I$ and to provide a further test of the specific $s_{I}$ intensity hypothesis. If a group is given very minimal $C R$ training prior to the 32 trials of $P R$ training. the $P R$ training should provide $R_{A p p r o a c h}$ counterconditioning to $s_{[}$intensities ranging from very weak to moderate. If so, persistence for such a group of Ss should be even weaker in early extinction and stronger in late extinction than it is in Group 16.32. In this experiment we added such a condition to the two conditions of Experiment I.

\section{Method}

\section{Subjects and Apparatus}

The Si were 30 male albino rats. approximately 9() day old. obtained from Holtzman I arms. Madjson. Wisconsin. Treatment of $5 s$ and apparatus was as described in Lisperiment 1.

\section{Procedure}

Three eroups of 10 Ss were run in L periment ll: ciroups 
4-32. 16-32. and 64-32. Procedural details were the sane as in Experiment I with one exception: Within each experimental day. Ss were run in rotation from their home cages, so that all 30 were given one trial before the first $S w$ as given the next trial Accordingly. the intertrial interval was approximately $40 \mathrm{~min}$ Running order was randomized between day's.

\section{Results and Discussion}

Analyses of variance were conducted on reciprocals of time scores from all alley segments. Again the results were sufficiently similar for all measures, so that only those from the start segment are reported. As can be seen in the bottom panel of Fig. 1. terminal acquisition performance for the three groups was almost identical. Early-EXT performance was again directly related to number of CR trials and late-EXT performance was inversely related to this factor. This result was supported by a highly reliable Groups by Days interaction $[F(18.932)=2.69, p<.01]$. Comparing Groups 16.32 and 64-32. Group 64-32 ran reliably faster over Days 1.5 $[F(1.932)=4.92, p<.05]$. while Group 16.32 ran faster over Days 7.10 $[F(1.932)=3.98 . p<.05]$. These data clearly replicate those from Experiment $I$.

The new group (4-32) ran slower in early extinction (Days 1-5) than Group 64-32 [F(1.932) $=4.37 . p<.05]$ and faster in later extinction (Days 7-10) $[F(1.932)=5.12, p<.05]$. Although Groups 4-32 and 16.32 differed in the predicted directions. the differences did not reach statistical significance.

The present findings support the view that resistance to extinction is determined by the similarity of intensity of $s_{\mathrm{F}}$ to which $\mathrm{R}_{\mathrm{A} p \mathrm{p} \text { roach has been }}$ counterconditioned and the intensity of $s_{F}$ present at a given stage of extinction. This $\mathrm{s}_{\mathrm{F}}$ intensity hypothesis. which has been proposed in other contexts (e.g.. Amsel. 1967: Traupmann. Wong. \& Amsel. 1971). provides greater specificity of prediction from the account of instrumental behavior that is known as frustration theory:

How do our results fit in with others in the CR-PR-EXT paradigm? Hothersall (1966) reported that total responses and total number of sessions to extinction were inversely related to amount of $C R$ preceding PR training. But. as we have indicated earlier. Hothersall did not present extinction response rates. A crude rate measure, the ratio of total extinction sessions to total extinction responses. suggests that response rates were directly related to amount of CR training. Assuming that the rate differences were manifest in early extinction. Hothersall's findings would be in line with other investigations of extinction in the free-operant barpressing situation in which number of $C R$ reinforcements have been varied (e.g.. Traupmann \& Porter. 1971): and they would not be incompatible with the specitic $s_{I}$ intensity hy pothesis.

We are now left with accounting for the Sutherland et al (1965) findings. For these investigators. a group given no $C R$ training before $60 \mathrm{PR}$ trials was more persistent as extinction progressed than a group given $100 \mathrm{CR}$ trials before 60 PR trials. There are two factors that might account for the absence in their experiment of the direct relationship between amount of $C R$ training and persistence that we observed during early extinction. First, Sutherland et al maintained their 90-day-old female rats on a 23 -h deprivation schedule: they were allowed to eat for $1 \mathrm{~h}$ daily. By' comparison, our 90-day-old males were fed $12 \mathrm{~g}$ a day. and they ate this in as little as $15 \mathrm{~min}$. So our Ss were likely trained under a higher drive. Second. Sutherland et al used as reward $10 \mathrm{sec}$ access to wet mash. While our Ss were given a 500-mg pellet that required about $30 \mathrm{sec}$ to consume. Allowing for the greater ease of eating wet mash, there is still the possibility that our Ss were trained with a larger reward. If Sutherland et al trained their Ss with a relatively low drive and small reward. it is possible that their primary frustration intensity would reach a ceiling that was no higher than our moderate level. Empirical findings support such reasoning both in relation to drive (McHose \& Ludvigson, 1964) and reward (Carlson, 1965) parameters. Since SF intensity must be taken as reflecting the intensity of primary frustration on the basis of which it is conditioned. $\mathrm{S}_{\mathrm{F}}$ would also have an upper limit at a moderate level. Assuming that the most intense $s_{F}$ to which $\mathrm{R}_{4}$ pproach was counterconditioned for the Sutherland et al Group C-P was moderate and that their Group $P$ received, toward the end of PR training. at least some counterconditioning to moderate levels of $\mathrm{SF}_{\mathrm{F}}$, these groups would not be expected to perform differently in early extinction. On the other hand, only their Group $P$ received counterconditioning to weak levels of $S_{F}$. since weak $S_{F}$ intensities were not available to Group C.P during PR training. Thus. as extinction progressed. Group $\mathrm{P}$ would be more persistent than Group C.P. This is. of course. highly speculative. Confirmation would require parametric investigations of the drive and reward variables in the CR.PR-EXT paradigm.

\section{REFERENCES}

Amsel. A. Partial reinfortement effects on vigor and persistence. In K. W. Spence and I. T. Spence (Eds.). The psichology of learning and motivation. Jell York: Academic Press. 1967

Carlion. 1. G. I rustratise nonreinforement of operant responding: Magnitude of reinforcement and response torce affect. Psichonomis Science. 1968. 11. 307-308.

Hothersall. D. Resistance to extinction when continuou. reinforement is followed by partial reinforcement. Jourmal of E \perimental Psrchology. 1966. 72, 109-112.

Mithose. J. H.. \& Ludvigson. J. II. Frustration effect as a function of drive. Psy hological Reports. 1964. 14. 371.373

Sutherland. I. S.. \& Makintosh. X. J. Wechanisms of animal discrimination leaming. lew York: Academic Press. 1971.

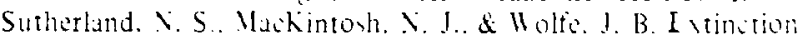
a a function of the otder of partial and ionsisent reinforement lourelal of L perimental Pucholue! logs. $60.56-59$ 
Theios. J.. \& Mleinnis. R. W. Partial rinturciment before and after continuous reintorcment. Inurmal of Experimental Psychology, 1967.73. $+79-481$.

Traupmann. K. L.. \& Porter. J. J. The oserlearning-extinction effect in free-operant bar prosing. Leaming \& Motivation. 1971. 2. 296-304.

Traupmann. K. L.. II ong. P. T. P.. \& Amsel. A. Durability of persistence as a tunction of number of partially reinfored trials. Joumal of lyperimental Pithology. 1971. 88 . 372-375.

\section{NOTE}

1. A later study by Theios and MiGinnis (1967) show's how some conclusions of Sutherland et al may be attributed to failure to consider terminal acquisition differences. However. this criticism does not offect the groups in the Sutherland et al study with which we are concerned. Group P (0 CR trials followed by $60 \mathrm{PR}$ trials and extinction) and Group C.P ( 100 CR trials followed by $60 \mathrm{PR}$ trials and extinction). The argument of the present paper applies only to these two groups, for which acquisition differences following PR training were insignificant.
(Recejved for publication March 14, 1973: accepted A pril 26, 1973.) 